\title{
Ecophysiologic characterization of various populations of esparto (stipa tenacissima $L$.) in Tunisia with respect to the constraint of the environment
}

\author{
Ben Sehil Soumaya ${ }^{1,2}$, Abdessamad Abdessalem ${ }^{1,2}$, Ksontini Mustapha ${ }^{1}$ And \\ Smiti Samira ${ }^{2}$ \\ ${ }^{1}$ : Laboratory of Forest Ecology, National Institute for Research in Rural Engineering, Water and Forests \\ (INRGREF), University of Carthage, 2080 Ariana, Tunis, Tunisia. \\ 2: Physiology Laboratory, Faculty of Sciences of Tunis, Campus Universitaire El Manar II, 2092 Tunis, Tunisia.
}

\begin{abstract}
This study investigates the effect of drought on six populations of esparto in Tunisia: Dj. Garen Elhalfaya (Kef), Dj. Elgarsi(Zaghouan), Dj. Touila(Kairouan), Dj. Elkhchem( Sidi Bouzid), Dj. Nadhour( Sidi Bouzid) and Dj. Hafi raso(Gabes) during the summer season. In order to see the response of the populations of esparto to the constraint of the environment by the determination of their hydric behavior (hydric potential) and physiological (stomatic conductance, density and size of the stomata). A strong variability is observed in the response of the populations of esparto to the drought as well for the hydric potential, the conductance, density that for the size of stomata accompanied by potentially adaptive variations to cope with the environmental changes. Indeed, the ability to maintain the stomata open at the mid-day and the variation in stomatal density and size are the most important effects in plants subjected to a hydric deficit. This leads to say that this species is resistant to drought for its water status and physiological behavior.
\end{abstract}

Keywords: populations of esparto, water stress, stomatic conductance, water potential, stomatal density.

\section{Introduction}

The surface of the tablecloths of esparto has undergoes an important degradation following an aggressive anthropic activity translated by overgrazing, clearing and overexploitation. This has left the slicks of esparto exposed to the constraints of environment not only edaphic but also climatic. All these parameters have a negative impact on its development and extension. From where need for studying and for analyzing the physiological behavior of this species with respect to its natural environment. Indeed, knowledge of the behavior and physiology of the stomata is one of the keys to understanding the development of the plants, because it is their opening which makes it possible to control the $\mathrm{CO}_{2}$ entry (necessary for the realization of photosynthesis) as well as the water loss by the plant. This dual stomatic function implies interactions between the two controlled processes [1].

The role of the stomata in the regulation of hydric flows and consequently in the adaptation to the stress is undeniable. Thus, their study has an interest for the determination of the tolerant populations to the drought [2].

\section{Plant Material}

\section{Materials And Methods}

Our study focused on tussocks esparto "Stipa tenacessima L." from different populations of slicks esparto of Tunisia: Dj. Garen Elhalfaya, Dj. Elgarsi, Dj. Touila, Dj. Elkhchem, Dj. Nadhour and Dj. Hafi Raso.

\section{Choice of the sites:}

\section{Methods}

The experiment was made in five sites of study localized in various areas: Kef, Zaghouan, Kairouan, Sidi Bouzid and Gabes. The choice was based according to the bioclimate, the geographical distribution and the relief. 
Tableau 1: Geographical, bioclimatic characteristics and of relief of various populations of esparto " Stipa tenacessima L. " in Tunisia.

\begin{tabular}{|c|c|c|c|c|c|c|c|}
\hline Site & Populations & code & Bioclimatic stage & Relief & Altitude & latitude & Longitude \\
\hline Kef & $\begin{array}{l}\text { Dj.Garen } \\
\text { Elhalfaya }\end{array}$ & Dj.G & Semi arid inferior & Mountain & 740 & $35^{\circ} 59^{\prime} 38^{\prime \prime} \mathrm{N}$ & $08^{\circ} 31^{\prime} 48^{\prime \prime} \mathrm{E}$ \\
\hline Zaghouan & Dj. ElGarsi & Dj.El & Semi arid inferior & Hill & 125 & $36^{\circ} 09^{\prime \prime} 22^{\prime \prime} \mathrm{N}$ & $10^{\circ} 13$ ' 43 '’ $\mathrm{E}$ \\
\hline Kairouan & $\begin{array}{l}\text { Hajeb Laayoun } \\
\text { Dj. Touila }\end{array}$ & Dj.T & arid superior & Mountain & 265 & $35^{\circ} 24^{\prime} 15^{\prime \prime} \mathrm{N}$ & $009^{\circ} 40^{\prime} 314^{\prime \prime} \mathrm{E}$ \\
\hline $\begin{array}{c}\text { Sidi } \\
\text { Bouzid }\end{array}$ & $\begin{array}{l}\text { Ouled Hafouz: } \\
\text { Dj. Elkhchem }\end{array}$ & Dj.E & arid superior & Montagne & 355 & $35^{\circ} 01 ', 42{ }^{\prime \prime} \mathrm{N}$ & $009^{\circ} 51^{\prime} 56^{\prime \prime} \mathrm{E}$ \\
\hline $\begin{array}{c}\text { Sidi } \\
\text { Bouzid }\end{array}$ & $\begin{array}{l}\text { Meknassi : } \\
\text { Dj. Nadhour }\end{array}$ & Dj.N & arid inferior & Hill & 330 & $34^{\circ} 37^{\prime \prime} 12^{\prime \prime} \mathrm{N}$ & $009^{\circ} 41^{\prime} 51^{\prime \prime} \mathrm{E}$ \\
\hline Gabes & $\begin{array}{l}\text { Matmata old: } \\
\text { Dj. Hafi raso }\end{array}$ & Dj.H & arid superior & Mountain & 495 & $33^{\circ} 30^{\prime} 33^{\prime \prime} \mathrm{N}$ & $010^{\circ} 01^{\prime} 01^{\prime \prime} \mathrm{E}$ \\
\hline
\end{tabular}

\section{Measurement of hydric and physiological parameters}

All measurements were performed during the summer period in August.

\subsection{Hydric Potential:}

The concept of "potential hydric" makes it possible to compare the hydric states of the physical environments (ground and its various layers) and biological (plant and its various bodies), and to determine the direction of circulation of water. It is expressed in mega Pascal or bars.

The kinetics of the hydric potential was followed at the level of each site, two measurements were taken, the first at dawn (basic hydric potential) the second at the mid-day (hydric potential of mid-day). Six repetitions were made for each measurement and the mean value was retained.

Leaf water potential was measured using a pressure chamber Scholander and al. (1965) [3] on well-developed leaves. Although destructive, this method has the advantage of being simple and fast.

\subsection{Stomatal conductance:}

The porometric techniques described by Laffray and Louguet (1989) [4] make it possible to determine the stomatic degree of opening by measuring the vapor flow emitted by the sheet using a porometer Standard Delta T. $\Delta \mathrm{P} 4$.

Each result represents the mean of nine measurements for the stomatic conductance of morning and mid-day.

\subsection{Density of stomata}

The stomatic density was obtained on epidermic impressions extracted by a colorless adhesive tape. This last was stuck on a blade for counting the number of stomata per mm2 under the microscope of the type Leica DM 2500 and was connected to one Computer on strips graduated in mm2. The determination of the stomatic density was carried out has different levels from the tuft of esparto. With each level, three sheets are selected: a young sheet, a sheet of median age and an old sheet.

For each sheet, three samples are used as repetitions to obtain a representative median value.

\subsection{Length and width of stomata}

Dimensions of the stomatic pores can be characterized by the length and the width of the ostiole. The measurement of these parameters was taken using a microscope type Leica DM 2500 and was connected to a computer on the same epidermic impressions used to determine the stomatic density.

\subsection{Statistical treatment}

The statistical analysis of the experimentation was carried out on the variables studied (hydric and physiological factors) in the natural conditions. It is carried out thanks to software SPSS version 17. The whole of measurements was the object of an analysis of variance ANOVA to a factor by the test F of Fisher to check the assumption of equality of the averages to the threshold of risk of 5\%. It is supplemented by multiple comparisons of the averages by the test of Newman and Keuls when the assumption of equality of the averages is rejected, [5, 6]. Graphical representations were performed with Excel XP.

\section{Study of hydric parameters}

\section{Results}

\subsection{Hydric Basic potential}

The values obtained are in the order of $-3.33,-3.75,-3.92,-2.69,-3.85$ and $-2.93 \mathrm{MPa}$, respectively for the sites of Dj. Garen Elhalfaya, Dj. Elgarsi, Dj. Touila, Dj. Elkhchem, Dj. Nadhour and Dj. Hafi Raso (Fig.1). 


\subsection{Hydric Potential of mid-day}

The values obtained are in the order of $-5.00 ;-4.75 ;-4.17 ;-4.20 ;-4.05$ and $-4.83 \mathrm{MPa}$, respectively for the sites of Dj. Garen Elhalfaya, Dj. Elgarsi, Dj. Stirred, Dj. Elkhchem, Dj. Nadhour and Dj. Hafi raso (Fig.1).

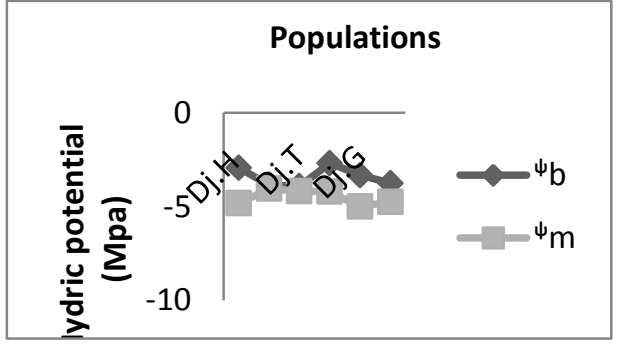

Figure 1: Variation of the hydric basic potential $(\psi b)$ and of the hydric potential of mid-day $(\psi \mathrm{m})$ for the various populations of esparto (stipa tenacissima L.) Dj. Garen Elhalfaya, Dj. Elgarsi, Dj. Touila, Dj. Elkhchem, Dj. Nadhour and $\mathrm{Dj}$. Hafi raso.

\subsection{The difference between the potential of mid-day and basic potential}

The values obtained are in the order of $1.67 ; 1 . ; 0.25 ; 1.51 ; 0.2$ and 1.9 respectively for the sites of $\mathrm{Dj}$. Garen Elhalfaya, Dj. Elgarsi, Dj. Touila, Dj. Elkhchem, Dj. Nadhour and Dj. Hafi raso (Fig.2).

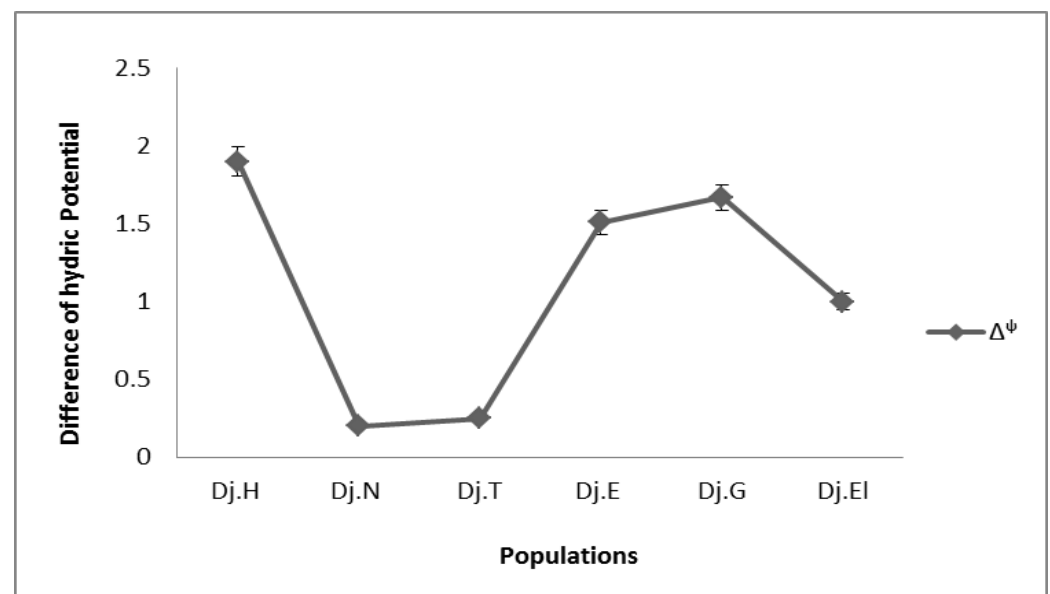

Figure 2: The difference of hydric potential $(\Delta \Psi)$ for the various populations of esparto (stipa tenacissima $L$.) $\mathrm{Dj}$. Garen Elhalfaya, Dj. Elgarsi, Dj. Touila, Dj. Elkhchem, Dj. Nadhour and Dj. Hafi raso.

\section{Study of physiological parameters.}

\subsection{Stomatic conductance of the morning}

The values obtained are in the order of $65.45 ; 54.62 ; 45.12 ; 39.32 ; 43.36$ and 40.05 $\mathrm{mmol} / \mathrm{m}^{2} / \mathrm{s}$, respectively for the sites of Dj. Garen Elhalfaya, Dj. Elgarsi, Dj. Touila, Dj. Elkhchem, Dj. Nadhour and Dj. Hafi raso (Fig.3).

\subsection{Stomatic conductance of the mid-day}

The values obtained are in the order of $85.5 ; 84.7 ; 70.6 ; 64.6 ; 35.5$ and $16.5 \mathrm{mmol} / \mathrm{m}^{2} / \mathrm{s}$, respectively for the sites of Dj. Garen Elhalfaya, Dj. Elgarsi, Dj. Elkhchem, Dj. Touila, Dj. Nadhour and Dj. Hafi raso (Fig.3). 


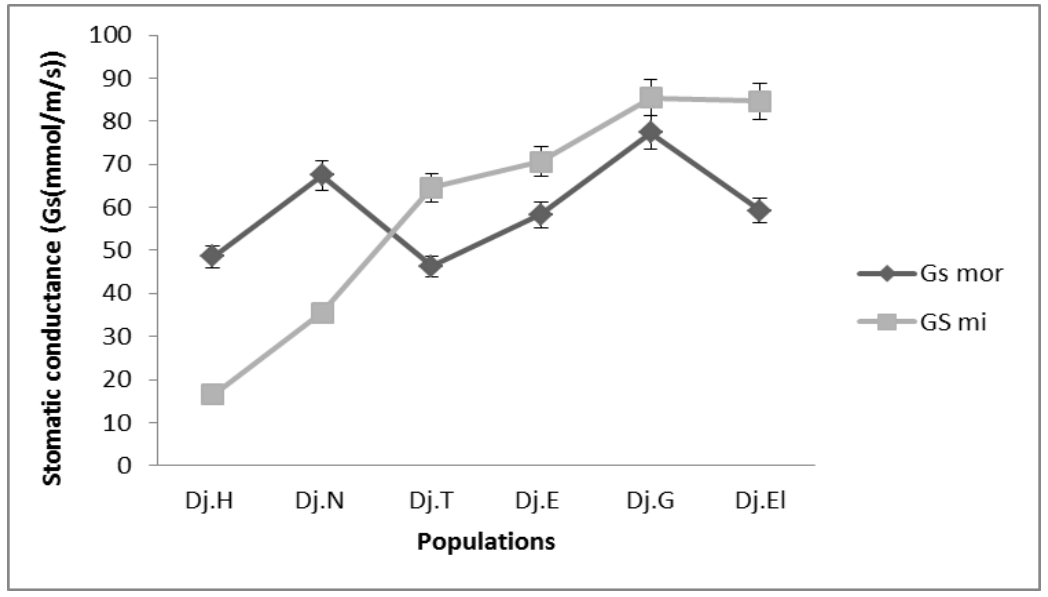

Figure 3 : Variations of the stomatic conductance of the morning (Gs mor) and mid-day (Gs mi) at the populatins of esparto (stipa tenacissima L.) of Dj. Garen Elhalfaya, Dj. Elgarsi, Dj. Touila, Dj. Elkhchem, Dj. Nadhour and Dj. Hafi raso.

\subsection{Stomatic density}

The values obtained are in the order of $164 ; 145 ; 108 ; 97 ; 94$ and 87 per $\mathrm{mm}^{2}$, respectively for the sites of Dj. Elgarsi, Dj. Touila, Dj. Hafi raso, Dj. Elkhchem et Dj. Garen Elhalfaya et Dj. Nadhour(Fig.4).

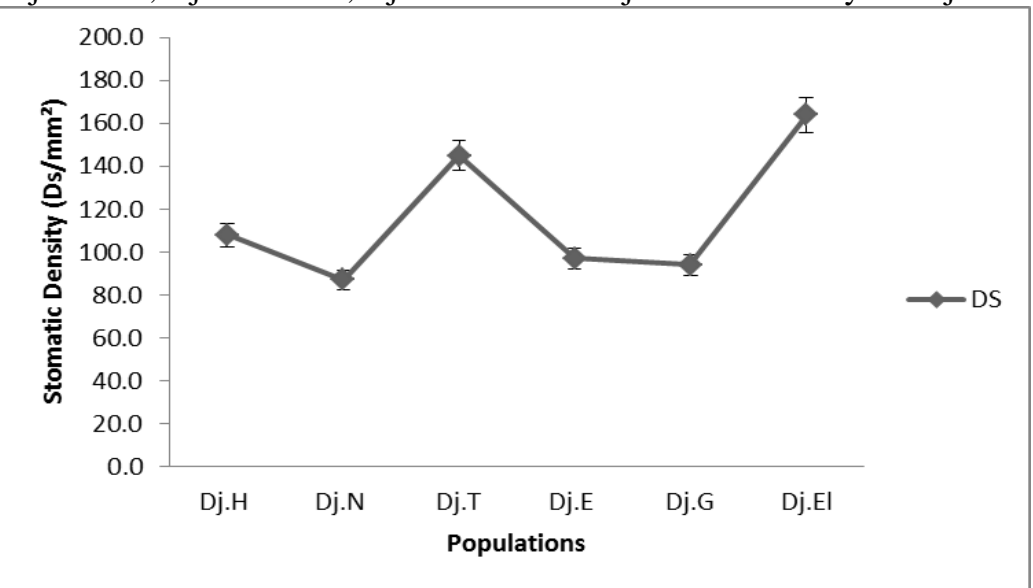

Figure 4: Density (by mm2) of the stomata (DS) at the populatins of esparto (stipa tenacissima L.) of Dj. Garen Elhalfaya, Dj. Elgarsi, Dj. Touila, Dj. Elkhchem, Dj. Nadhour and Dj. Hafi raso.

\subsection{Length of the stomata}

The values obtained are in the order of $6.06 ; 5.64 ; 5.57 ; 4.81 ; 4.09$ and $3.55 \mu \mathrm{m}$, respectively for the sites of Dj. Elkhchem, Dj. Hafi raso, Dj. Garen Elhalfaya, Dj. Nadhour, Dj. Elgarsi and Dj. Touila (Fig.5).

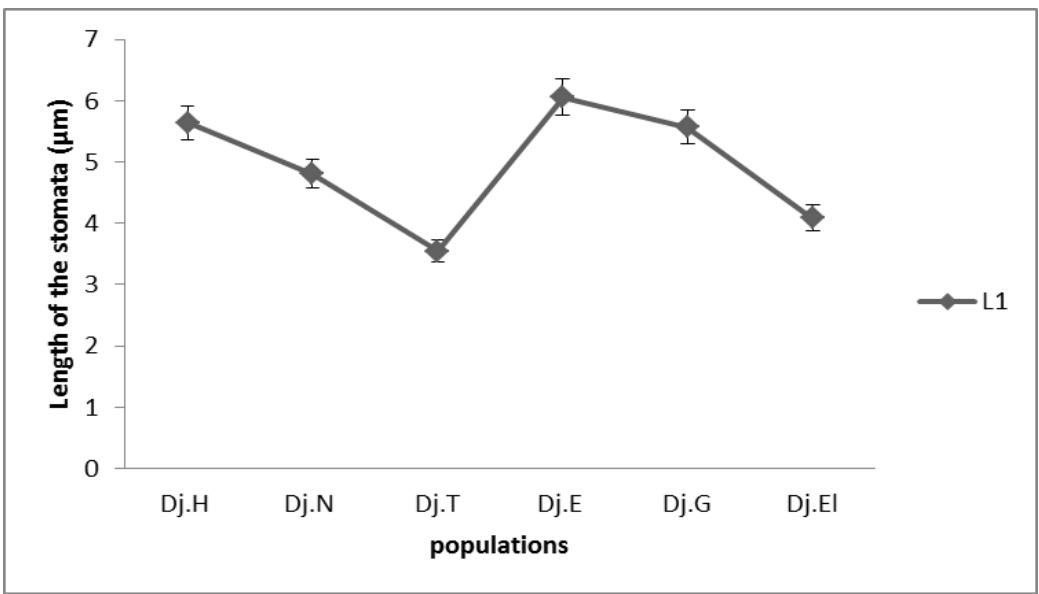

Figure 5: Length $(\mu \mathrm{m})$ of the stomata (L1) at the populatins of esparto (stipa tenacissima L.) of Dj. Garen Elhalfaya, Dj. Elgarsi, Dj. Touila, Dj. Elkhchem, Dj. Nadhour and Dj. Hafi raso. 


\subsection{Width of the stomata}

The values obtained are in the order of $1.62 ; 1.45 ; 1.28 ; 1 ; 0.76$ and $0.7 \mu \mathrm{m}$, respectively for the sites of Dj. Touila, Dj. Elkhchem, Dj. Garen Elhalfaya, Dj. Hafi raso, Dj. Nadhour and Dj. Elgarsi (Fig.6).

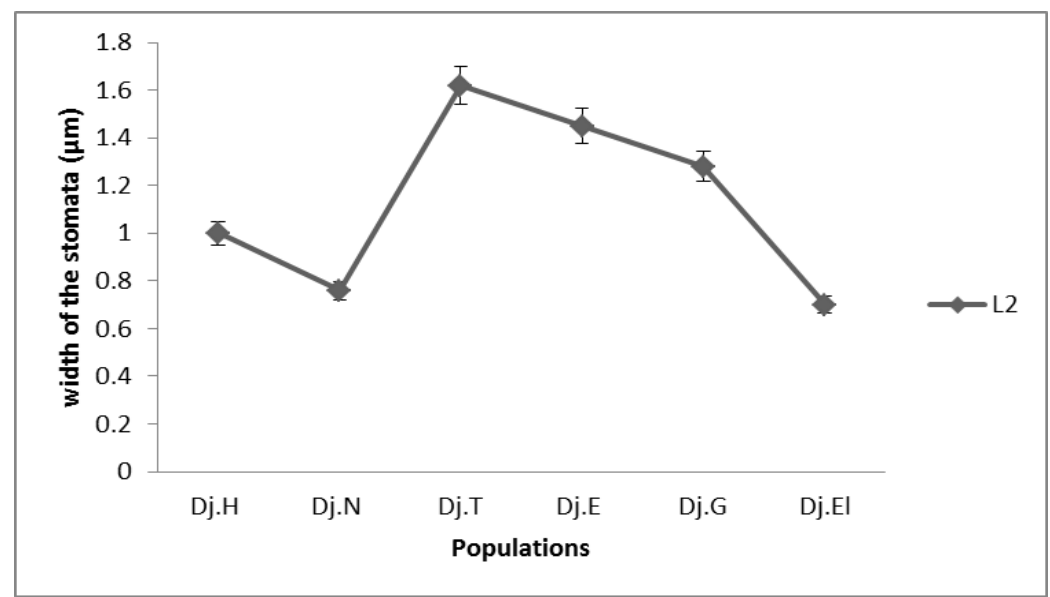

Figure 6: Width $(\mu \mathrm{m})$ of the stomata (L2) at the populatins of esparto (stipa tenacissima L.) of Dj. Garen Elhalfaya, Dj. Elgarsi, Dj. Touila, Dj. Elkhchem, Dj. Nadhour and Dj. Hafi raso.

\section{Study of hydric parameters}

\section{Discussion}

The values of the hydric basic potential obtained indicate a hydric constraint in all the stations with a minimum to Dj. Elkhchem (-2.69 MPa) and Dj. Hafi raso (- 2.93 MPa), important in Dj. Garen Elhalfaya ($3.33 \mathrm{MPa})$ and very important in $\mathrm{Dj}$. Touila $(-3.92 \mathrm{MPa})$ in August. The basic potential is an indicator of the hydric state of the ground in the rhizospheric zone (Bationo, and al, 2001) [7] and this depends on the speed of drying of the ground, of its reserve usable, but also of the mass of the ground prospected by the roots [8].

The maintenance of a high hydric potential is related on the aptitude to extract water from the ground and to the capacity to limit the water losses by transpiration [9].

The hydric potential of mid-day is higher in Dj. Garen Elhalfaya and Dj. Hafi raso (-5; -4.83 MPa) and presents a minimum to $\mathrm{Dj}$. Nadhour $(-4.05 \mathrm{MPa})$ this gives that the potential of mid-day $(\psi \mathrm{m})$ is correlated with soil humidity and transpiration.

(Ksontini, 1996) [10], Louguet (1978) [11] attributes the reduction in the hydric potential of the leaf to the reduction in the hydric potential of the ground.

The difference between the hydric potential of mid-day and basic, watch of the values raised at the populations of Dj. Hafi raso, Dj. Garen Elhalfaya et Dj. Elkhchem, $(1.67 ; 1.9 ; 1.51)$ and with a least degree for Dj. Elgarsi (1), while it is low for Dj. Nadhour et Dj. Touila $(0.2 ; 025)$. This shows that the most important degree of adaptation to the drought is at the populations of $\mathrm{Dj}$. Hafi raso and $\mathrm{Dj}$. Garen Elhalfaya. The evaluation of the hydric state of vegetables by the measure of the foliar potential, allows characterizing their answers to the factors of the environment [12].

\section{Study of physiological parameters}

Our results showed that the values of the stomatic conductance of the mid-day are higher at the populations of Dj. Garen Elhalfaya and Dj. Elgarsi, $\left(85.5 ; 84.7 \mathrm{mmol} / \mathrm{m}^{2} / \mathrm{s}\right)$, of least degree at $\mathrm{Dj}$. Elkhchem and $\mathrm{Dj}$. Touila $\left(70.6\right.$ et $\left.64.6 \mathrm{mmol} / \mathrm{m}^{2} / \mathrm{s}\right)$ indicating a strategy of adaptation to the drought and a resistance more marked at the populations of $\mathrm{Dj}$. Garen Elhalfaya and $\mathrm{Dj}$. Elgarsi. One hypothesis has been that it is drought resistant plants at the cellular level are often able to keep their stomata open and therefore have a high potential for $\mathrm{CO} 2$ assimilation during severe hydric deficits [13].

While those of Dj. Nadhour and Dj. Hafi raso $\left(35.5 ; 16.5 \mathrm{mmol} / \mathrm{m}^{2} / \mathrm{s}\right)$ express a partial stomatic closing at the mid-day. Beyschlag and al [14], signal that the sheets of the plants which reduce their stomatic conductance in the middle of the day close only some stomata, whereas the others remain open. Indeed, in case of drought the plant is confronted with two types of stresses contradictory: to open these stomata to increase the gain of carbon by the photosynthetic activity or to close them to reduce the water transpiratoire losses, the ideal situation would be that the plant can regulate its stomatic conductance during the day in order to minimizing water loss for the total amount of assimilated carbon [15]. Genotypes with low conductance are more 
susceptible to vapor deficit and lower leaf hydric potential genotypes with high conductance. Low conductance is generally proposed as a favorable trait for adaptation to drought [9].

\section{Study of the stomatic density}

Our results showed that the highest values of the stomatic density are recorded at the populations of $\mathrm{Dj}$. Elgarsi et $\mathrm{Dj}$. Touila $(164 ; 145)$ and weakes at the populations of $\mathrm{Dj}$. Hafi raso, Dj. Elkhchem, Dj. Garen Elhalfaya and $\mathrm{Dj}$. Nadhour $(108 ; 97 ; 94 ; 87)$. The increase in stomatic density by the lack of water in the plant has been observed by some authors [16,17, and 18].

However, Dhawan et al [19] have shown that the availability of the water can affect the stomatic frequency of Leucoena leucocepha.This high number of stomata ensures a cooling of the sheet leading to a lower tissues temperature, which promotes photosynthesis [20].

While work Kuruvadi (1989) [21] on wheat, showed that it meets hydric stress by a reduction of the stomata density.

For dry land populations the stomatic conductance is positively correlated with the density of the stomata thus the gaseous exchanges seem to be more controlled by the number of stomata than by the stomatic regulation. In the same way for the population of $\mathrm{Dj}$. Elgarsi, which is part of the semi-arid bioclimatic lower however, the opposite phenomenon was observed at the population of $\mathrm{Dj}$. Garen Elhalfaya pertaining on the same bioclimatic floor as the latter (Fig.7). Indeed the density of the stomata can vary according to the living conditions of the plant [22]. However, some authors consider that resistance to the hydric deficit is not related to the number, but with the operation of the stomata. On this subject, Katerji and Bethenod (1997) [23] noticed that clear photosynthesis at the sunflower is weaker than that of corn in spite of the lowest number of the stomata of the latter.

For the size of the stomata, our results showed that the increase amongst stomata per foliar unit of area was accompanied by a reduction of the width and the length of stomata for the population of $\mathrm{Dj}$. Elgarsi. Generally at a stressed plant, the density of the stomata increases, which causes a reduction in width and length of their opening, as it is the case of the argan tree in a mining pollution [24] and at two varieties of olive-tree subjected to a hydric stress [25]. The increase in the stomatic density can increase the clear assimilation of $\mathrm{CO} 2$ [26] and decrease the water loss: indeed a high number of stomata can generate stomata of small-sized and with fast closing. Lange and al [27], noted that for changes of steam pressure of water between the sheet and the atmospheric air, these stomata answer by a closing partial of their ostioles.

Whereas to the other populations, the decrease of the number of stomata by foliar unit area was accompanied by an increase in width and in length of the stomata where the population of DJ. Elkhchem possesses the longest and the widest stomata (Fig.8). Indeed, the decrease in the density of stomata does not always translate by a reduction of the losses in water by the plant, because of its compensation by the increase of their size $[28,29]$. The changes of the size of the stomata by environmental stresses were already reported in the literature. Indeed the density of the stomata can vary according to the living conditions of the plant. Their size is variable also according to the species and depends within the same species on the position on the sheet on the plant and the conditions on development. Thus, any factor which affects the growth of the sheet can affect the development of the stomata, their form, their dimension and their number [21].

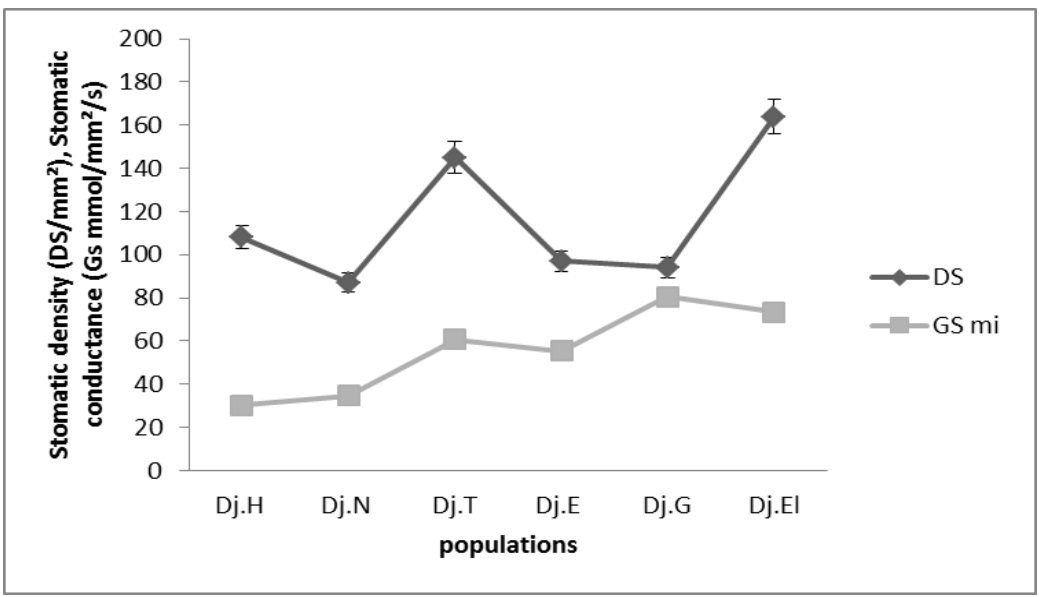

Figure 7: Variations of the stomatic conductance (Gs mi) at the mid-day and of the density (DS) (by mm2) of stomata in different populations of esparto (stipa tenacissima L.) ( Dj. Garen Elhalfaya, Dj. Elgarsi, Dj. Touila, Dj. Elkhchem, Dj. Nadhour and Dj. Hafi raso). 


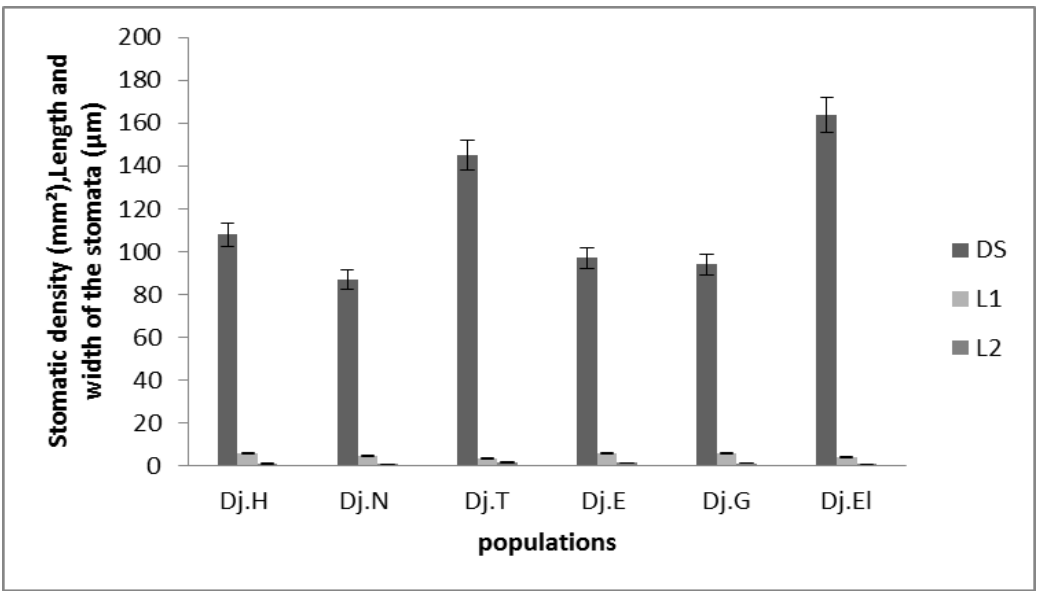

Figure 8: Variations of density (DS) (by mm2), length $(\mathrm{L} 1, \mu \mathrm{m})$ and width $(\mathrm{L} 2, \mu \mathrm{m})$ of stomata in different populations of esparto (stipa tenacissima L.) ( Dj. Garen Elhalfaya, Dj. Elgarsi, Dj. Touila, Dj. Elkhchem, Dj. Nadhour and $\mathrm{Dj}$. Hafi raso).

\section{Conclusion}

A variability of response with respect to the constraint environment during the summer season was noted for all the populations of esparto studied even that which is part of the same bioclimatic stage. The capacity to maintain the stomata open at the mid- day and the variation of the density of the stomata, as well as their size, are the most important effects at the plants subjected to a hydric deficit. Indeed, the eco physiologic characterization of the tufts of esparto of the various populations made it possible to note that the studied parameters, (hydric potential, the conductance, density and size of the stomata) can differentiate between the various populations of esparto in Tunisia.

All these observations and comparison of the results of hydric statute and physiological behavior of the esparto realized in natural conditions make it clear that the constraint of the environment induces the best performances for the adaptation to the drought.

\section{References}

[1] Dreyer,E., 1997: Photosynthesis and drought in forest trees. Trees-Contributions to Modern Tree Physiology. (Rennenberg, H., Eschrich, W. \&Ziegler, H., eds.). Backhuys Publishers,pp. 215-238.Edit.Francaise de l'ouvrage portugais a la subericulture.

[2] Miskin, K.E., Rasmusson, D.C., et Moss, D.N. 1972. Inheritance and physiological effects on stomatal frequency in barley. Crop. Sci., 12: 780-783.

[3] Scholander P.F., Hammel H.T., Bradstreet E.D. and Hemmingsen E.A., 1965. Sap pressure in vascular plants science 148: 338-346.

[4] Laffary.d et Louguet P., 1989 : l'appareil stomatique et la résistance à la sécheresse. Rev. Res. Amelior. Prod. Agr. Milieu Aride, vol. I p. 31-46.

[5] Steel Robert G. D., Torrie H., - 1980 Principles and procedures of statistics. A biometrical approach. McGraw-Hill Book Company, $633 \mathrm{p}$.

[6] Dagnelie P., 1986: Théorie et méthodes statistiques. Applications agronomiques.2 :463. Presse Universitaire de Gembloux. Belgique.

[7] Bationo B.A.,Ouedraogo S.J, Alexandre D-Y., Guinko S., 2001: Statut hydrique de quatre espèce ligneuses soudaniennes dans la forêt de Nazinon, Burkina Faso. Science et changement planétaire/ Sècheresse. Volume 12, Numero 2, 87-94, Juin 2001, Notes originales.

[8] Baldy C., 1986. Agrometerologie et développement des régions arides et semi- arides. INRA,Paris, 114p.

[9] Turner NC., 1986: Adaptation to water deficit: a changing perspective. Aust J Plant Physiol; 13: 175-90.

[10] Ksontini M. ,1996: Etude ecophysiologique des réponses à la contrainte hydrique du chêne liège (Quercus suber) dans le NordTunisie: comparaison avec le chêne Kermès ( $Q$. coccifera) et le chêne zeen (Q.faginea) Thèse université Paris XII Val De Marne, $157 \mathrm{p}$.

[11] Louguet P., 1978: Les stomates: Caractères principaux et mécanismes de leur mouvement In : Photosynthèse et production vegetale.Ed.Gauthier Villard.195. 219.

[12] Ritchie G.A.et Hinckley T.M., 1975: The pressure chamber as an instrument for ecological research.Adv.Ecol.Res.9: 165.254.

[13] Clavel D., Drame N.K., Diop N.D., Y Z-F., 2005. : Adaptation à la sécheresse et création variétale : le cas de l'arachide en zone sahélienne. Oléagineux corps gras lipides, Volume 12, Numéro 3, 248-60, Mai Juin 2005.

[14] Beyschlag W, Pfanz H. A., 1990: fast method to detect the occurrence of nonhomogeneous distribution of stomatal aperture in heterobaric plant leaves. Experiments with Arbutus unedo L. during the diurnal course. Oecologia 1990; 82: 5

[15] Rejeb M.N., 1992 : Etude des mécanismes de résistance à la sécheresse du caroubier (ceratonia siliqual L.). Thèse de doctorat d'état es sciences naturelles Fac. Sci. Tunis. 199p 2-5.

[16] Mougou A. Évaluation de la résistance à la sécheresse par des paramètres morphologiques, écophysiologiques et biochimiques chez plusieurs espèces de tomate. Thèse de docteur en sciences agronomiques, Gand (Belgique), 1984.

[17] Lichtenthaler HK, Buschmann C, Doll M, and al., 1981: Photosynthetic activity, chloroplast ultrastructure, and leaf characteristics of high-light and low-light plant and sun and shade leaves. Photosynth Res 1981; 2: 115-41.

[18] Masarovicova E, Minarcis P., 1984: Photosynthetic response and adaptation of Fagus sylvatica L. trees to light conditions. I. Growth of leaves, shoot and trees. Biologia (Bratislava) 1984; 39: 867-76. 
[19] Dhawan V, Bhjwan SS., 1984: Hardening in vitro and morpho-physiological changes in the leave during acclimatization of micropropagated plant of Lucaena leucacephala. Plant Sci 1987; 53: 65-72. (Bratislava); 39: 867-76.

[20] Mahjoub-Boujnah D. Variations morphologiques et écophysiologiques en rapport avec la résistance à la sécheresse chez l'olivier (Olea europaea L.). Thèse de docteur en sciences agronomiques. Gand (Belgique), 1997.

[21] Kuruvadi, S. (1989): Stomatal frequency in bread wheat under irrigated and rainfed conditions. Rachis, 8: 22-28.

[22] Ticha I., 1982. Photosynthetic characteristic during ontogenrsis of leaves.7. stomata density and sizes. Photosynthetica, 16: 375-471 p.

[23] Katerji N., Bethenod O., 1997- Comparaison du comportement hydrique et de la capacité photosynthétique du maïs et du tournesol en conditions de contrainte hydrique. Conclusion sur l'éfficience d'utilisation de l'eau. Agronomie, 17: 17-24 p.

[24] Alilou, H., Rouhi R., et Idrissi Hassani L. M .2006. Effet de la pollution minière sur les paramètres stomatique chez Argania spinosa (L.). Biology and biotechnology, 5: 41-45.

[25] Guerfel. M., 2008: Caractérisation morphologique structurale et biochimique de l'adaptation à la sécheresse chez l'olivier (Olea europea L.). These de doctorat. Fac.Sci.Tunis. 161p.

[26] Terashima I., Araya T., Miyazawa S.I., Sone K.,et Yano S., 2005. Construction and maintenance of the optimal photosynthetic systems of the leaf, herbaceous plant and tree: an eco- development treatise. Ann. Bot, 95: 507-519 p.

[27] Lange OL, Losch R, Schulze ED, Kappen L. Responses of stomata to changes in humidity. Planta 1971; 100: 76-86.

[28] Sapra, V.T., Hughes, J.L., and Sharma, G.C. 1975. Inheritance and physiological effects of stomatal frequency in Barley. Crop. Sci., 11: 780-783.

[29] Wang, H., and Clarke, J.M. 1993. Genotypic, intraplant and environmental variation in stomatal frequency and size in wheat. Can. J. Plant Sci., 73: 671-678 